\title{
Correction to: Migration, FDI, and Welfare
}

\section{Paul Comolli ${ }^{1}$}

Published online: 3 September 2018

(C) International Atlantic Economic Society 2018

Correction to: Atl Econ J (2018) 46:179-188

https://doi.org/10.1007/s11293-018-9579-5

In the published article, Figure 1 is incorrectly reproduced. The correct figure is given below:

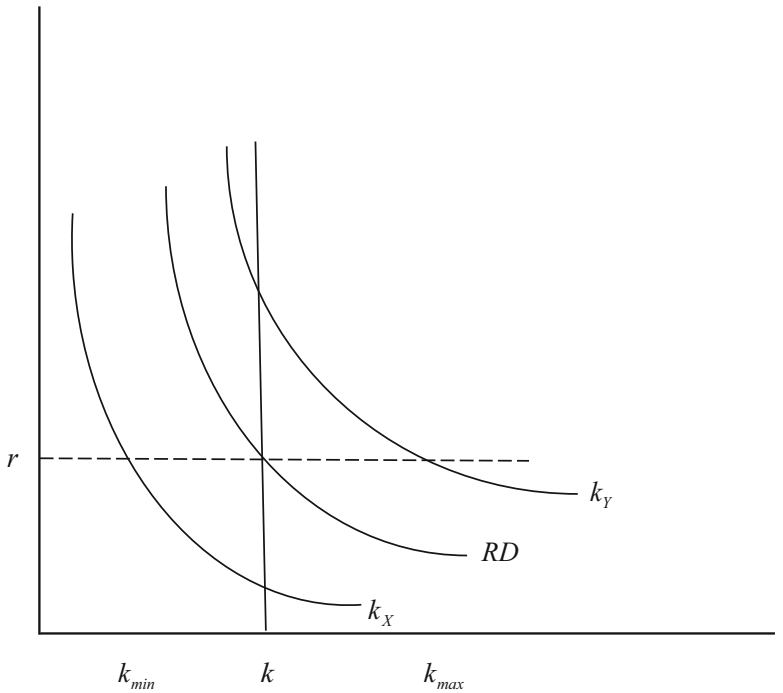

Fig. 1 Hypothetical factor market in the Heckscher-Ohlin model where $k$ is the aggregate relative supply of capital, $R D$ is the aggregate relative demand for capital, and $r$ is the given rental rate. The relative demand for capital in sectors $X$ and $Y$ are represented by $k_{X}$ and $k_{Y}$, respectively. When $k=k_{\text {min }}$, the country completely specializes in $\operatorname{good} X$, and when $k=k_{\max }$, the country completely specializes in $\operatorname{good} Y$

The online version of the original article can be found at https://doi.org/10.1007/s11293-018-9579-5

Paul Comolli

pcomolli@ku.edu

1 Department of Economics, University of Kansas, 434 Snow Hall, Lawrence, KS 66045, USA 